\section{MEDICAL NEWS,}

Eratum.- In the report of the discussion on Hospital Isolation and the Disinfection of Patients in the Section of Public Medicine which was published in the BrItisH MEdiCAL JOURNAL of August 31st, certain remarks on disinfection on p. 524 were erroneously attributed to F. Fraser, M.D., M.O.H. Sevenoaks Union. The speaker was Dr. A. Mearns Fraser, D.P.H., of Chelmsford.

Dr. Hans von Becker has been appointed Physician in Ordinary to the Khedive, in succession to Comanos Pacha, who lately resigned that position. Becker Bey is an Austrian and at one time practised in Vienna, where he acquired some reputation as a specialist in diseases of children. For some years he has been connected with the Crown Prince Rudolph Hospital in Cairo.

\section{MEDICAL VACANCIES.}

The following vacancies are announced:

BRIGHTON, HOVE, AND PRESTON DISPENSARY, Queen's Road, Brighton.-Medical Officer for the No. 6 District. Applications to the Secretary by September 9 th.

CHESTERFIELD AND NORTH DERBYSHIRE HOSPITAL AND DISPENSARY, Chesterfield. Resident House-Surgeon, tenable for two years. Salary, floo per annum, with board, apartments, and
laundries. Applications and testimonials to the secretary before September 19th.

CITY OF LONDON HOSPITAL FOR DISEASES OF THE CHEST, Victoria Park, E-House-Physician. Board and residence and allowance for washing provided. Appointment for six months. Also Assistant Physician; must be M. or F.R.C.P. Lond. Applications to the Secretary for the for

DERBYSHIRE ROYAL INFIRMARY, Derby.-Clinical Assistant; must be qualified and registered under the Medical Acts of Students of Medicine, who have only their Final Examination to pass. Appointmactory service will be given, and board, residence, and washing. Applications and testimonials to Walter G. Carnt, secretary, before September 13th.

GENERAL HOSPITAL, Nottingham.-House-Physician. Appointment for two years, but eligible for re-election. Salary, £100 per annum, rising 110 a year to $£ 120$. Assistant House-Surgeon. Appointment
for six months. Board, lodging, and washing in hospital; no salary. for six months. Board, lodging, and washing in hospital; no salary. Applications to the Secretary for the

GLASGOW MATERNITY HOSPITAL.-Obstetric Physician and Assistant Obstetric Physician. Applications to Arthur Forbes, Secretary, 146, Buchanan Street, Glasgow, by November 8th.

GREAT YARMOUTH HOSPITAL.-House-Surgeon. Must be doubly qualified and able when required to give lectures for probationer nurses. Salary, £90 per annum, with board and lodging. Applications and testimonials to R. F. E. Ferrier, Honorary Secretary, before September 14th.

LANCASTER INFIRMARY AND DISPENSARY.-House-Surgeon; unmarried. Must be doubly qualified and registered. Salary, £80, with residence, board, attendance, and washing. Applications to Allan
Sewart, Honorary Secretary, before September 12th.

METROPOLITAN HOSPITAL, Kingsland Road, N.E.-House-Physician, House-Surgeon, Assistant House-Physician, and Assistant HouseSurgeon. Appointments tenable for six months. The House-Physia year. Must possess a registered English medical and surgical qualia year. Must possess a registered English medical and surgical qualitary, before September 9th.

NORTH CAMBRIDGESHIRE HOSPITAL, wisbech. - House-Surgeon; fully qualified. Salary, $£ 130$ per annum, with detached house (furnished), coals, gas, and water provided. Applications and testimonials to Mr.

PLYMOUTH PUBLIC DISPENSARY.-Second Medical Officer of the Provident Department. Appointed for one year, but eligible for reelection; doubly qualified. Remuneration will be the net profits (after deduction of the expenses mentioned in the Scheme). Applications to the Honorary Secretary, w. H. Prance, 7, Athenæum Terrace, Plymouth, by September 11th.

ROTHERHAM HOSPITAL AND DISPENSARY.-Assistant House-Surgeon. Doubly qualified, and registered. No salary, board, lodging, and washing. Applications and testimonials to the House-surgeon by October 1st.

ROYAL UNITED HOSPITAL, Bath.-House-Surgeon. Candidates must be M.R.C.S.Eng. and registered. Appointment for one year. Salary monials to W. Stockweil, Secretary-superintendent, before September 11th.

ST. BARTHOLOMEW'S HOSPITAL AND COLLEGE.-Assistant Demonstrator of Chemistry. Applications to Thomas W. Shore, Warden, be-
ST. BARTHOLOMEW'S HOSPITAL.-Assistant Physician. Candidates must be Fellows or Members of the Royal College of Physicians, Lon don. Applicants must attend the Court of Governors to be held on Henry Cross, Clerk, by September 9 th.
Hens

\section{MEDICAL APPOINTMENTS.}

FEGEN, C. M., M.R.C.S., L.R.C.P. and Diploma in State Medicine, appointed Medical Officer of Health to the Ampthill Rural District

GouLD, J. E., M.D., L.R.C.P.Lond., reapp

HALLIGAN, Dr., appointed Medical Officer for the Ballyroan Dispensary District of the Abbeyleix Union, vice Dr. Fitzgerald, resigned.

HAWARD, H. H., B.A.Cantab., L.R C.P., M.R.C.S., appointed Clinical Assistant in the Ear Department of St. Thomas's Hospital.

HoME, A. L.. L.R.C.P., M.R.C.S., appointed House-Surgeon to St. Thomas's Hospital.

JENNER, L. L., M.A., M.B., B.Ch.Oxon., M.R.C.P.(extension), appointed Kesident House-Physician to St. Thomas's Hospital.

LaYron, F. G., L.R.C.P., M.R.C.S., appointed non-resident House-Physician to St. Thomas's Hospital.

Louden, M. M.., M.D., appointed Public Vaccination Officer for the Arundel District of the East Preston Union.

MACINTYRE, H., M.B., C.M.Glasg., appointed Assistant Medical Officer to Shoreditch Infirmary, vice Dr. Pearce, resigned.

ORCHARD, Edward, M.B., C.M.Aberd., appointed Medical Officer of Health to the Kingussie and Irish Parish Council.

PALIN, E. W., M.A., M.B., B.Ch.Oxon., L.R C.P., M.R.C.S., appointed Clinical Assistant in the Ear Department of St'. Thomas's Hospital.

Pearse, R. E. Franklyn, L.R.C.P.Lond., M.R.C.S.Eng., reappointed Africa.

PRAIN, J. L., L.R.C.P., M.R.C.S., appointed Assistant House-Surgeon to St. Thomas's Hospital.

Yearstey, P. Macleod, F.R.C.S., appointed Clinical Assistant to the Central London Throat and Ear Hospital.

\section{BIRTHS, MARRIAGES, AND DEATHS.}

The charge for inserting announcements of Births, Marriages, and Deaths is 38. 6d., which sum should be forwarded in post office order or stamps with the notice not later than Wednesday morning, in order to ensure insertion in the current issue.

BIRTHS.

Brierley.-On Sunday, September 1st, 1895, at Old Trafford, the wife of James Brassey Brierley, M.D., of a son.

STAVELEY.-August 13th, at 13, South Eaton Place, S.W., the wife of W. H. C. Staveley, F.R.C.S., of a son.

TAYLOR.-On August 26th, at Aylesford, Kent, the wife of Herbert Edward Taylor, B.A., M.D.Dub., of a daughter.

Williams.-On August 9th, 1895, at Fishkill-on-Hudson, New York. the wife of George Herbert Williams, M.D., M.R.C.S.Eng., L.R.C.P.Edin.,
of a daughter-Helen Merritt.

\section{MARRIAGES.}

DALDY-HITCHCOCK.-On the 3rd inst., at St. George's Church, Bloomsbury, by the Rev. R.A. Hitchcock, assisted by the Rev. G. E. Hitchcock, brothers of the bride, and the Rev. A. B. Boyd-Carpenter, Arthur Mantell Daldy, M.D., son of O. G. Daldy, Esq., of Romford, to Mary Ellen, only daughter of the Rev. Canon Hitcheock.

HACKETT-WYNNE-JONES.-August 28th, at St. Mary's Church, Pembroke, Surgeon-Major R. I. Dalby Hackett, M.A.A. M.D., Army Medical Staff, to Evelyn Miary W
House, Pembroke.

MACNAI3-Dening:-On June 20th, at Thandiani Hazara, Punjab, by the Rev. F. J. Montgomery, M.A. Chaplain of Hazara, Surgeon-Captain Allan J. Macnab, Indian Medical service, "Q.O." Corps of Guides, eldest son of the late Alexander Macnab, C.E., to Honoria, eldest daughter of Lieutenant-Colonel L. Dening, D.S.O., Commanding 26tl
Punjab Infantry.

WEBB-BAXTER.-August 28th, at Stockport, Frederick J. Webb, M.B. etc., Beech House, Gorton, Manchester, to Emily, daughter of George Baxter, Esq., Fleet, Lincolnshire.

YELF-BARNARD.-August, at Christ Church, Gloucester, by the Revs. Vaughan Payne and Alfred J. Barnard, Jolnn Burnet Yelf, M.R.C.S. L.R.C.P., Shipston-on-Stour, to Blanche Mary, eldest daughter o

\section{DEATHS.}

ALDRIDGE. - On August 27th last, in London, suddenly, Russell Aldridge, M.D., L.R.C.S., L.S.A., J.P., Consulting Surgeon Yeovil District Hospital, Certif. Factory Inspector, etc., aged 64 .

BuxroN.-At 10, Albert Terrace, Blackpool, on August 23rd, Evelyn Regiment, and A.M.D.

STEVENSON-On August 29th, at Whitby, from accidental drowning Harold Thomas Stevenson, aged 27, elder son of Thomas Stevenson, M.D., F.R.C.P., of Sandhurst Lodge, Gresham Road, S.W.

Tномson.-At 11, Barnes Street, Ayr, on September 2nd. James Johnstone, infant son of Dr. Gemmill Thomson, aged 13 months. 